\title{
DIFFERENT SENSOR SYSTEMS FOR THE APPLICATION OF VARIABLE RATE TECHNOLOGY IN PERMANENT CROPS
}

\author{
Davor PETROVIĆ, Mladen JURIŠIĆ, Vjekoslav TADIĆ, Ivan PLAŠČAK, Željko BARAČ
}

\begin{abstract}
The paper presents a review of different sensory systems for trees' characterization and detection in permanent crops and the detection of plant health status in crop conditions for the purpose of applying the variable application rate. The use of new technologies enables the use of variable inputs in production with the aim of increasing the economic profit and reducing the negative impact on the environment. World trends increasingly emphasize the use of various sensor systems to achieve precision agriculture and apply the following: ultrasonic sensors for the detection of permanent crops; LIDAR (optical) sensors for treetop detection and characterization; infrared sensors with similar characteristics of optical sensors, but with very low cost prices and $\mathrm{N}$ - sensors for variable nitric fertilization. The daily development of sensor systems applied in agricultural production improves the performance and quality of the machines they are installed on. With a more intensive use of sensors in agricultural mechanization, their price becomes more acceptable for widespread use by achieving high quality work with respect to the ecological principles of sustainable production.
\end{abstract}

Keywords: agriculture; crop protection; sensors; sprayers; treetop; variable rate technology (VRT)

\section{INTRODUCTION}

In the current agricultural production, the application of pesticides implies a uniform application throughout the plant or crop area, resulting in an increased risk of environmental contamination and the use of larger norms. Therefore, more modern world trends emphasize the importance of applying sensors and precision agriculture to the rational use of pesticides. That is why it is very important to know the geometric properties of permanent crops and the possibility of applying a variable spreading standard with respect to the optimum dose required to control pests, with the least impact on the environment. Geometric characteristics of a plant or crops are fundamental information on the basis of which the variable rate technology can be applied. Although conventional sprayers are equipped with sensor systems that are more cost-effective in exploitation (reducing pesticide consumption per unit area), they are still not available for a wide range of farmers due to relatively high prices. Due to this problem, research on new technologies and the possibility of reducing spray rates are intensified with the aim of a rational use of pesticides, reduction of production costs and protection of the entire agro-ecosystem.

With regard to the given above, and with the increasement in the automatization of agricultural systems, sensors are becoming the main compoment for the collection and transmission of information. In this review, is primarily used for the detection and geometrical characterization of a treetop for satisfying pesticide protection of permanent crops. In the advancement of technology, sensors are getting more and more perfect and they are present in many processes in agriculture, such as measuring, controlling and regulation [1, $2,3,4,5,6 \ldots]$.

In the context of precision agriculture and variable rate technology, sensors are also used in plant scanning to provide information on the plant grow phase and needs for nitrogen. These types of sensors use reflected light to measure the the normalized difference of vegetation index (NDVI). By gathering this information of plant health, it is possible to determine the norm for nitrogen fertilization. This approach has already been effectively used in crops such as corn and wheat $[7,8,9]$. Similar research is carried out with the aim of determining the N-norm by using special optical sensors $[10,11]$.

\section{VARIABLE RATE TECHNOLOGY (VRT)}

The crop property variability estimation within one growing plot can be useful in achieving the use of input data. The technological progress over the past decade has enabled the development of technology with variable application standards (VRT) that, according to current needs, enables input optimization.

The sensory approach to using variable input technology does not require mapping and data collection, but real-time sensors read and accept the current situation in the field or in the permanent plantation. Based on the currently measured data, the variable rate of the application of the pesticide, fertilizer or irrigation is determined. The sensorspecific variable rate does not require the application of a GPS system, but if the mentioned system is available during application, it can be used in future technological operations.

The application of new technologies in agriculture is growing rapidly as the need for a more precise application leads to a reduction in the use of chemical products (pesticides and mineral fertilizers), and remarkable savings are achieved by taking care of the ecological aspect, i.e the sustainability of agricultural production. Sophisticated equipment, which is built in agricultural machines for performing all technological operations (soil treatment, fertilization, plant protection, harvesting the fruits, etc.) has been used. More and more agricultural machinery today is equipped with smart sensors that can detect a large number of properties, ranging from crop health and water needs to 
the level of nitrogen in the soil. By applying conventional methods of management in permanent crops, the trees' age and shape, treetop size and volume, soil property variability and other things are neglected.

The best example of the application of variabale rate technology (VRT) in agriculture is the use of different sensory systems for crop protection in permanent crops. The use of different sensor types (ultrasonic, infrared and optical) through the application of variable rate technology represents the future of crop protection for permanent crops in mind of ecological, economic and exploitation improvement. With regard to the mentioned above and with the siginificance of crop protection in modern agriculture, the main goal of this paper is to problematize this part of agicultural technology.

Moreover, the sensory approach for the application of VRT is very often used for mineral fertilizer dosage. Thus, the rest of this chapter is concentrated on this property. Many authors are concerned with the research of variable application of fertilizers, determined by the yields and soil nutrition analysis in permanent crops [12]. Maps for the variable application of nitrogen on treetop structure are produced by using GPS and ultrasonic sensors [13]. Research shows that the nitrogen level can be adjusted according to the trees' size, but not according to the plantation's age, thus leading to $38-40 \%$ savings. By using LIDAR sensors, the treetop characteristics have an effect on the irrigation reduction possibility and variable fertilizers' applications have been determined by [14].

The VRT use in field crops is based on the sensory approach to light reflection measuring from plants and the collected data analysis. By varying the luminous flux on the sensor, which depends on individual plant properties, an electronic signal is sent to the regulator which performs the dosing device opening and the particular medium's application.

In practice, the sensory approach is applied to controlling weeds on agricultural areas and is used for nitrogen fertilization. The $\mathrm{N}$ - sensor system is based on the ability to recognize the nitrogen fertilizer standard by measuring light reflection from plants. Where reflection is higher, the leaf chlorophyll content is lower, i e, there is a greater need for nitrogen and vice versa. In this way, it is possible to apply the corresponding, larger doses to the part of the fields showing signs of greater nitrification loss, and in order to achieve a uniform yield on all field parts. By exploitation of $\mathrm{N}$ - sensors, many factors may appear that can affect the reading accuracy, such as the following: different sensor distance to the leaf, the appearance of dew on leaf surface and cloudy weather - different intensity of light reflection from the leaf to the sensor, and getting inaccurate results. Asner, G.P. et al. [15] states that the main factor that prevents the accurate reading of leaf colour is the light reflection from the ground. This problem is more expressed at the lower LAI index and in earlier vegetative phases [16]. One of the solutions to avoid these problems is to put sensors to a higher level for a more vertical leaf evaluation where LAI is uniform and the reflection from the ground is minimal. Furthermore, in order to avoid the mentioned problems, Pena-Yewtukhiw, E. M. et al. [17] states that the use of a larger number of sensors (8) can reduce the error.

The use of sensor systems for achieving variable application norms is more suitable for permanent crops, since by using the said system, it is possible to quantify each individual tree in the plant by measuring its height and width. By using the selective pesticide application, the greatest savings are achieved in younger permanent crops, due to large spaces within the rows that are not filled with treetops, and at vacant sites of old plantations.

\section{SENSOR SYSTEMS FOR THE APPLICATION OF PESTICIDES IN PERMANENT CROPS}

\subsection{Sensors}

As it has already been mentioned mentioned, the development of sensory systems for detecting the presence and shape of permanent plant breeding has recently been evident. Sensors convert the measured physical size (altitude, width, volume, etc.) to analogue electrical (current, voltage, resistance) or digital information. The operating principle of the sensor is based on the interaction with the surrounding objects, and the reaction is transformed into an output signal and controlled by the technological process. There are a number of physical phenomena that can be applied when making a sensor. The measurement of nonelectric signals (optical, infrared, inductive and the like) begins by conversion to electrical signals, after which processing is performed.

Table 1 An overview of the main charasterictics of sensors

\begin{tabular}{|c|c|c|c|}
\hline $\begin{array}{c}\text { Characteristics/Sensors } \\
<2 \mathrm{~m}\end{array}$ & LIDAR & Ultrasonic & Infrared \\
\hline $\begin{array}{c}\text { Range measurement: } \\
2-30 \mathrm{~m}\end{array}$ & $\mathrm{o}$ & ++ & + \\
\hline $\begin{array}{c}\text { Range measurement: } \\
30-100 \mathrm{~m}\end{array}$ & ++ & - & + \\
\hline $\begin{array}{c}\text { Angle measurement: } \\
<10^{\circ}\end{array}$ & ++ & - & ++ \\
\hline $\begin{array}{c}\text { Angle measurement: } \\
<30^{\circ}\end{array}$ & ++ & 0 & ++ \\
\hline Angular Resolution & ++ & - & ++ \\
\hline Direct Velocity Information & -- & 0 & -- \\
\hline Operation in the Rain & o & o & o \\
\hline Operation in Fog or Snow & - & + & 0 \\
\hline $\begin{array}{c}\text { Operation if there is Dirt on the } \\
\text { Sensor }\end{array}$ & o & ++ & - \\
\hline Night Vision & n.a. & n.a. & ++ \\
\hline
\end{tabular}

Source:http://writingaboutcars.com/wpcontent/uploads/2015/11/Different_sensors.p ng [19]

++ ideally suited; + good performance; o possible, but drawbacks to be expected; only possible with large additional effort; - - impossible; n.a. not applicable

It is important to know that each sensor has its own limitation; limited measurement accuracy that may vary depending on different field conditions. With the future development of sensory systems in agriculture, it is expected that the efficiency and accuracy of the measurement will be increased [18]. An overview of the main sensor properties is shown in Tab. 1. 


\subsection{Ultrasonic Sensors}

Ultrasonic sensors serve to determine the distance and function according to the principle of the difference in the time interval required for the ultrasonic wave to pass from the sensor to the detected object and back (Fig. 1). They consist of an ultrasonic transceiver, an output signal generator and an amplifier. The transceiver periodically emits an ultrasonic wave frequency of $10-400 \mathrm{kHz}$ and then receives a reflected wave from the detected object.

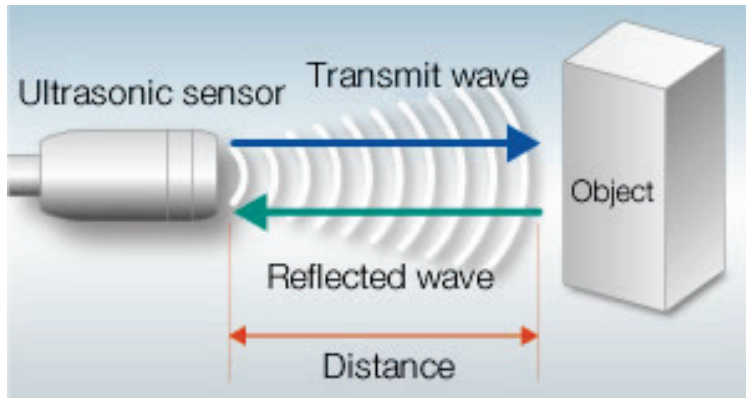

Figure 1 The operation principle of ultrasonic sensors [20]

The detection of the object's distance based on the time required for the ultrasonic wave to pass from the transmitter to receiver is basically simple, but there are several shortcomings: temperature dependence and air pressure, light intensity decrease due to radial expansion and absorption, noise effects, etc.

The most common type of ultrasonic sensor construction is in the form of a prism or a cylinder. The transceiver head may be separated from the electronic part, enabling it to be installed at inaccessible locations. The use of ultrasonic sensors in agriculture is as an idea taken from the industry, where they are used to measure different distances and determine the presence of objects [21]. Fig. 2 shows the complete system of ultrasonic sensors with electromagnetic valves and the control unit used on the sprayers.

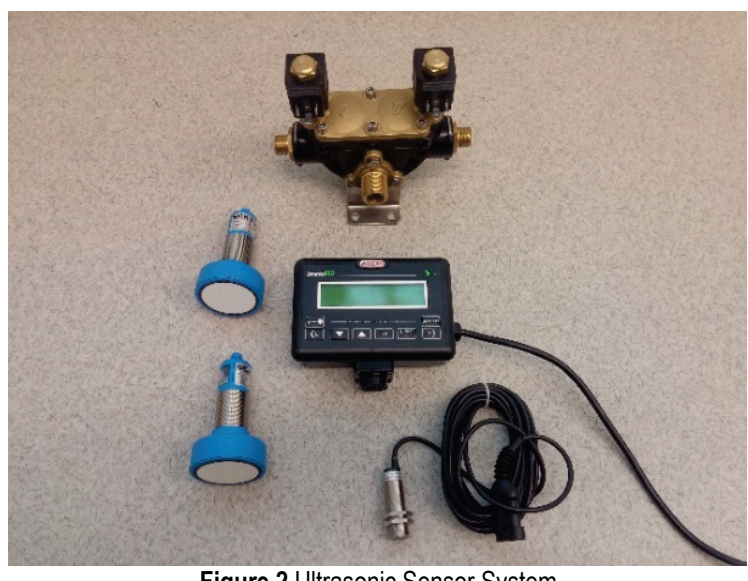

Figure 2 Ultrasonic Sensor System

The main advantage of this type of sensor is their robust design. It reduces the negative impact of an adverse working environment (humidity, vibration, dirt, temperature, fog) and has a relatively low cost price with respect to other electronic circuits used for the same purpose [8]. Their main disadvantage is the large angle of the divergence of ultrasonic waves, which is why the limited resolution, i.e the accuracy of the measurement [21] is limited.

Authors [22, 23] develop a simple system based on ultrasonic sensors with an intermittent dispersion method, where sensors engage / disengage electromagnetic valves at the pressure regulator. This application method enables the savings on pesticides of $10-17 \%$ in peach plantation and in apple plantation of 20 to $27 \%$. By developing the sensor management algorithm, savings of $28-34 \%$ and $36-52 \%$ are achieved in the same plantations [24].

Balsari, P. and Tamagnone, M. [25] state that during the research, sensors have had the ability to recognize branch diameters of 3 to $4 \mathrm{~cm}$, while the minimum void they could detect was $35 \mathrm{~cm}$. With advanced technology, today's ultrasonic sensors have the ability to recognize gaps between crowns of just a few inches. The precision of ultrasonic sensors is influenced by various factors: treetop distance, temperature, humidity and velocity of motion [26]. The use of a detector capable of detecting the treetop and its shape has been explored by aa whole series of authors, with the aim of an accurate plant's treetop detection and a significant reduction in drift protection [2; 27-30]. Llorents, J. et al. [4] use ultrasonic sensors to determine plant geometry for a more precise determination of the spraying rate with the aim of drift reduction.

Jejčić, V. et al. [31] develop an automatic spraying system, where computer-controlled spraying is achieved by the use of ultrasonic sensors and an RGB camera. The automatic system is tested at a speed of $3 \mathrm{kmh}^{-1}$ where, with respect to the control sensor-free spraying, the savings of $20.2 \%$ per each nozzle are achieved. The same authors state that the deposit, distribution and surface coverage remained unaltered by the use of sensory spraying.

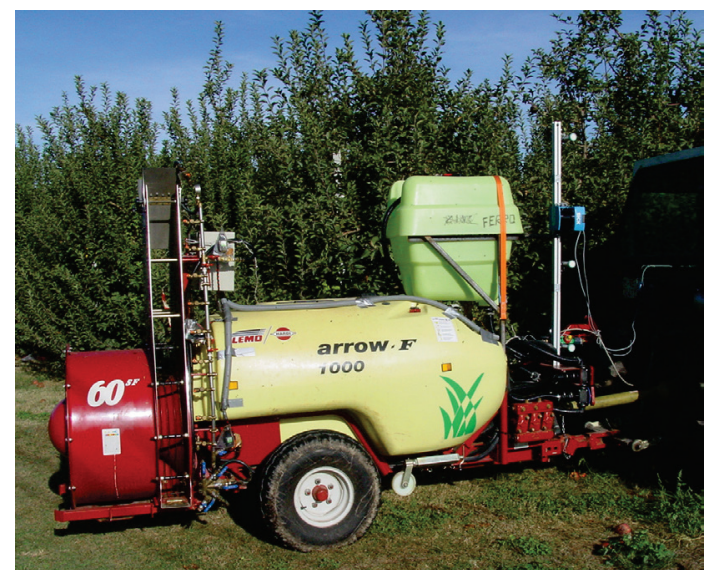

Figure 3 Ultrasonic and LIDAR sensors equipped air assistance sprayer [40]

Llorents, J. et al. [32] state that by incorporating electronic parts into conventional sprayers, the spraying technique is significantly improved and the risk of spraying outside the targeted space of plant protection is reduced. Sensor system equipped dispersers, used for permanent crops' protection, base their functions on the determination of three basic parameters: tree detection, leaf mass density 
and treetop structure, i.e breeding [33]. The determination of the geometric shape and the treetop presence are relatively complex tasks because of the treetop's geometrical characteristics, which are directly related to tree growth and development.

Real-time treetop recognition by using ultrasonic sensors is investigated by many scientists around the world $[1 ; 5 ; 34$ 42]. The treetop shape directly affects the deposition of pesticides, and thus the effectiveness of spraying. The variable application air assistance sprayer prototype, equipped with ultrasonic and LIDAR sensors for treetop shape detection, is shown in Fig. 3.

The usage of ultrasonic sensors in agricultural production has been tested on several factors. One of the key factors is the distance of the sensor from the treetop and the speed of the sprayer's movement. If the distance of the sensor is smaller, the echo ultrasound wave (echo signal) will be of greater intensity, and thus the accuracy of the measurement, while by increasing the distance, the echo signal is weakened and errors occur when reading the results [14]. If the treetop is at a small distance between the treetop and the sensor, the possibility of interference between the two sensors increases and the reading accuracy decreases [43]. According to the above mentioned authors, the average reading error in laboratory conditions is $\pm 0.53 \mathrm{~cm}$, while in field conditions, the detection error is $\pm 5.11 \mathrm{~cm}$, taken on the average. By analyzing the obtained results, it can be concluded that it is very important to determine the correct distance between the ultrasonic sensors with respect to the width of the angular ultrasound waves and the distance from the detected treetop. In Fig. 4, a test platform with differently positioned ultrasonic sensors for determining a reasonable distance between sensors and treetops, with the aim of preventing the interference, is shown.

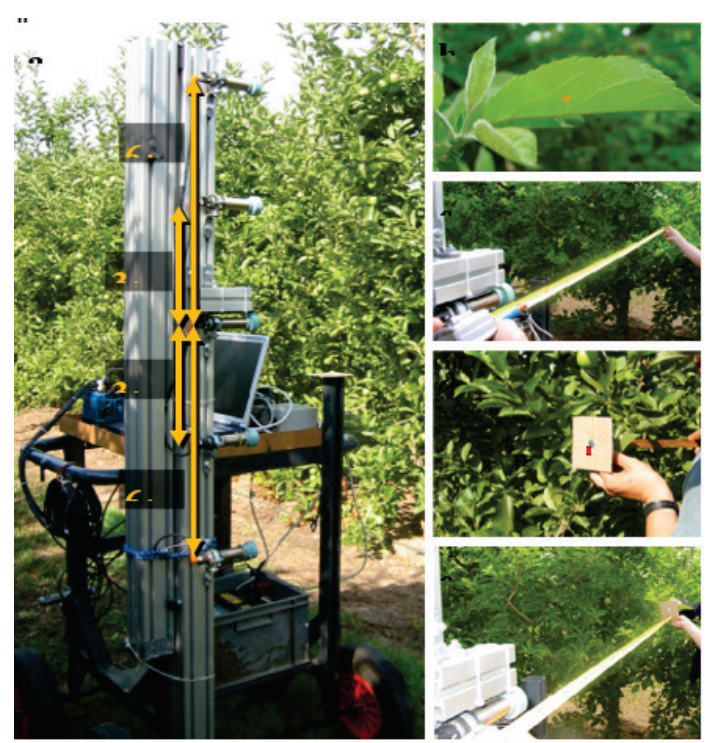

Figure 4 Test platform with ultrasonic sensors [42]

Palleja, T. and Landers, A. [43-44] explore the possibility of using cheap ultrasonic sensors to determine treetop density during vegetation. The results obtained show a high degree of correlation between the leaf mass increase and the feedback ultrasonic wave towards the sensor, but the system is not able to determine the actual leaf mass density in the crown. The same authors [45-46] develop a sensor system to identify treetop density, on the basis of which it is possible to adjust air velocity and the liquid amount during spraying.

Authors [47] compare two methods of treetop density determination in the plantation: PQA (Point Quadrat Analysis) - biomass contact probe procedure and ultrasonic sensor system. The results obtained show a very high level of the sensory method acceptability for the treetop density determination. However, it should be noted that calibration, according to the tree type, is required for each crop individually, so that the readings could be used to set the sprayer in real time. Due to the above-mentioned echo signal issues, many authors continue with studying the ultrasonic sensor systems' usage.

$\mathrm{Li}, \mathrm{H}$. et al. [48] explore the model for treetop density determination that is examined in laboratory conditions, comparing the control model of leaves put in four layers, chosen as optimal, and models with a different number of leaves' layers. The obtained results show a reading error of between 17.68 and $29.92 \%$, in comparison with the control model. According to the above mentioned authors, the ultrasound system tested is sufficiently precise for the variable rate technology usage (VRT).

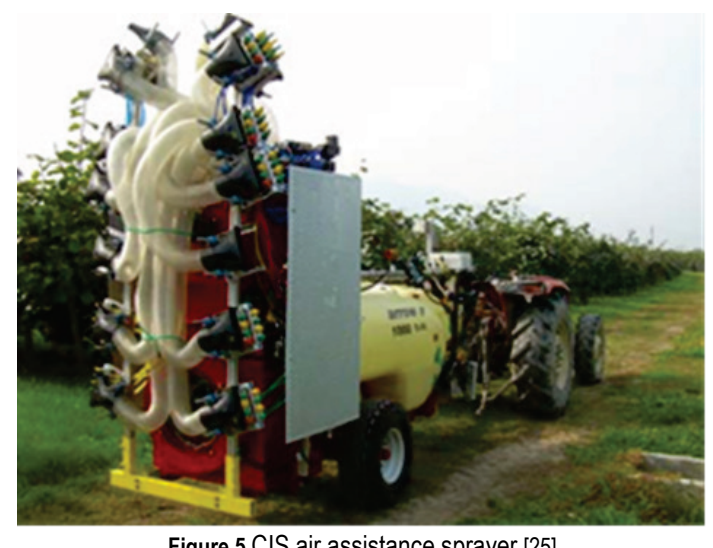

Figure $5 \mathrm{CIS}$ air assistance sprayer [25]

The CIS (Crop Identification System), equipped with a GPS system, meteorological station, ultrasonic sensor system and a special set of different, electromagnetic valves equipped, nozzles, and used for permanent crops' protection, is at present the most modern system for the VRT usage (Fig. 5). The CIS sprayer works on the principle of a permanent crop current state's recognition, with respect to the position, current weather conditions (temperature, relative humidity, air velocity and wind direction), treetop presence and shape, and based on the above information, the computer determines the nozzle type (standard or anti drift) and the spraying norm.

\subsection{LIDAR Sensors}

LIDAR (Light Detection and Ranging) is an optical measuring instrument for laser dispersion which is repelled by very small particles in the Earth's atmosphere (aerosols, 
clouds, etc.), and then registered in an optical receiver. The principle of operation is based on changing the parameters of the optical signal with a change in physical size, and these sensors do not have galvanic or magnetic connections. The laser beams obtain for each crop slice a variable number of identified points according to the distance to the sensor and the angle from the horizontal. These sensors are often called optical sensors, and they are shown in Fig. 6.

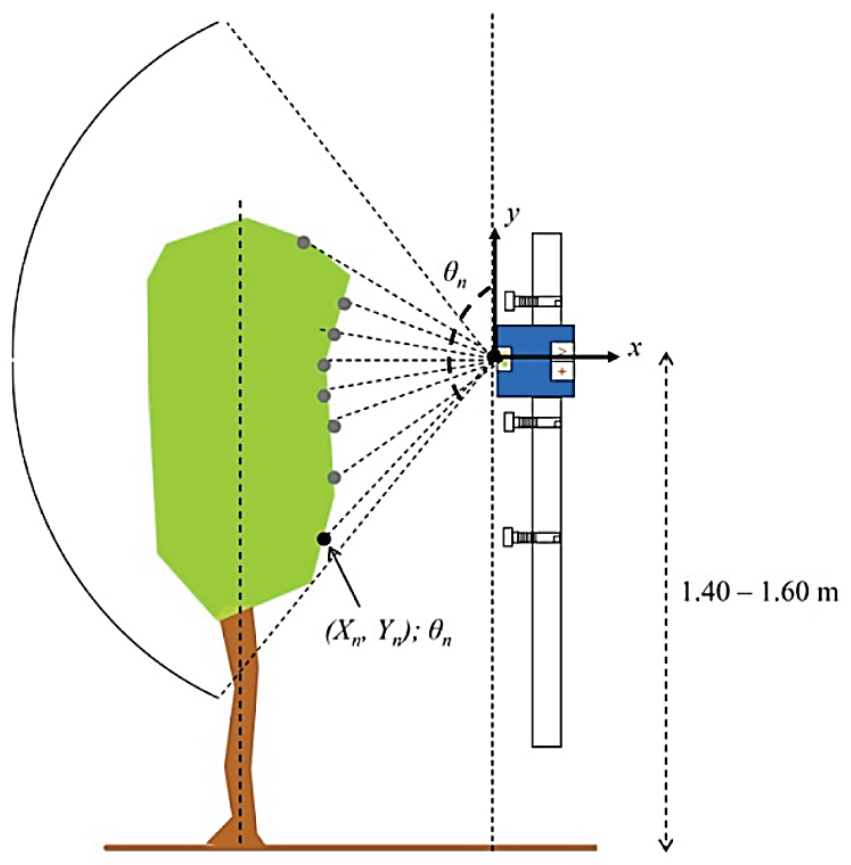

Figure 6 Functioning principle of the LIDAR sensor [4]
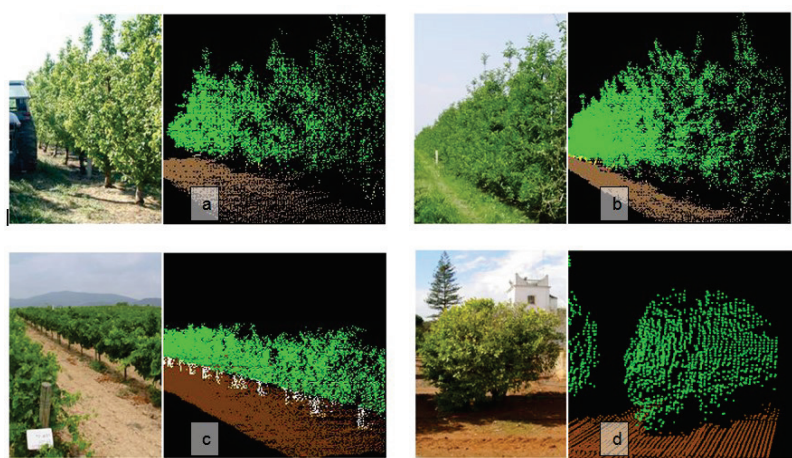

Figure 7 Pictures of different crop training systems and their corresponding 3D images obtained by the LIDAR system: pear trees (a), apple trees (b), vineyards (c) and citrus trees (d) [49]

This type of sensor can be used under all conditions of a strong magnetic field, high temperature, electric noise and chemical corrosion, and are much more flexible and reliable than ultrasonic sensors. The bad sides are: the complexity of signal production and its processing, a demand for the optical visibility between the receiver and the transmitter, and the sensitivity to mechanical vibration.

LIDAR sensors are used for almost all applications without the contact detection of objects at a great distance, and the material of the object for detection is almost inessential. Given the above mentioned characteristics, the application possibility is multiple. Fig. 7 shows the reading mode using the LIDAR sensor.

Escola, A. et al. [40] research the accuracy of measurements between two types of sensors (ultrasonic and LIDAR sensors) to determine the treetop volume. The results show that LIDAR sensors are more accurate due to the measurement method because they detect in between 180 and 720 dots. When applied, the variable applications of both sensor types have achieved satisfactory results, but when using a LIDAR sensor, it is possible to determine the trees' geometric structure. Their ability to quickly measure the distance between the sensors and the objects allows 3D images of the treetop shape ( $\mathrm{x}, \mathrm{y}$ and $\mathrm{z}$ axis) and applying the appropriate algorithms, allowing the digital display of the treetop structure $[50,51,52]$. The mentioned sensors for surface area and leaf mass volume determination have been used as an alternative to manual methods that are expensive, time-consuming and cause treetop damage, when sampling the leaf.

Llorens, J. et al. [4] compare the measurement accuracy between the use of ultrasonic and LIDAR sensors with a manual measurement of plant volume (height, width and leaf mass volume). The obtained results show that ultrasonic sensors can successfully determine average plant characteristics, while LIDAR sensors achieve greater accuracy and more detailed information on the treetop shape. They are very suitable for the usage at longer distances because they have high spatial resolution and detection speeds, and can be used for fluid loss determination in the air drift form. When spraying, drifted liquids' detection outside the targeted object of protection has been possible with LIDAR sensors and has successfully replaced the use of passive collectors [51]. Compared to passive collectors, LIDAR sensors achieve high accuracy of spatial data, require fewer workforce, shorter data collection time, and no additional chemical analysis is required [52].

\subsection{Infrared Sensors}

Infrared sensors are one more type of active sensors, used to determine the treetop distance and presence and work on the transmitting and receiving light flux principle. This sensor type research has been being carried out in different directions, hence a system consisting of five, sprayer located, infrared sensors that recognize treetop presence, shape and density has been being developed by the scientists at the Cornell University. By using the sensor information obtained, the airflow decreases or increases as needed. In this way, the protective agent saving of $40 \%$ at the beginning of vegetation is achieved, while the decrease in the vineyard drift is $71-63 \%$ [53]. The research carried out in China includes the infrared sensors' usage, mounted on the sprayer with an electrostatic spraying system. The sensors are placed in three levels in order to detect the treetop presence and shape. Using this system, pesticide saving in between 50 and $75 \%$ [54] has been achieved. 


\section{CONCLUSION}

Mechanical, chemical, biological and process size measurements are carried out using various measuring transformers - sensors. Their application is based on the development of materials and technologies, the integration of components and the application of micromechanics and microelectronics. As part of the advanced technology systems, sensors have become one of the inevitable parts that enable communication between the machine and the computer. Through the daily development of sensors applied in agriculture, their effect on the production process is improved. The sensors' cost price is getting smaller as well, which is why they become more accessible for use on a wide range of agricultural machines and systems. Previous research conducted over the past two decades show that ultrasound sensors are successfully used for detecting treetop presence, while the LIDAR sensor can achieve greater accuracy and give more detailed information.

Despite their low price, the use of infrared sensors is in the initial stages of research. All types of explored sensors obtain useful information for the specific spraying factors' determination. When it comes to plant protection, they ensure a satisfactory biological efficiency with a reduced liquid drift occurrence during application, unlike the conventional application systems.

\section{REFERENCES}

[1] Stajnko, D., Berk, P., Lešnik, M., Jejčič, V., Lakota, M., Štrancar, A., Hočevar, M., \& Rakun, J. (2012). Programmable ultrasonic sensing system for targeted spraying in orchards. Sensors, 12, 15500-15519. https://doi.org/10.3390/s121115500

[2] Llorens, J., Gil, E., Llop, J., \& Escola, A. (2010). Variable rate dosing in precision viticulture: use of electronic devices to improve application efficiency, Crop Prot., 29, 239-248. https://doi.org/10.1016/j.cropro.2009.12.022

[3] Doruchowski, G., Swiechowski, W., Godyn, A., \& Holownicki, R. (2011). Automatically controlled sprayer to implement spray drift reducing application strategies in orchards, J. fruit Ornam. Plant Res., 19, 175-182.

[4] Llorens, J., Gil, E., \& Llop, J. (2011). Ultrasonic and Lidar sensors for electronic canopy characterization in vineyards: Advances to improve pesticide application methods. Sensors, 11(2), 2177-2194. https://doi.org/10.3390/s110202177

[5] Perry, R. \& Cordero, R. (1995). Sensor controlled orchard sprayers. Proceedings of the National Conference on Pesticide Application Technology, Guelph, 164-171.

[6] Koch, H., Weisser, P., Cross, J., Gilbert, A., Glass, C., Taylor, W., Walklate, P., \& Western, N. (2000). Sensor equipped orchard spraying-efficacy, savings and drift reduction. Pesticide application, University of Surrey, Guildford, UK, 1718, 357-362.

[7] Raun, W., Solie, J., Stone, M., Martin, K., Freeman, K., Mullen, R., Zhang, H., Schepers, J., \& Johnson, G. (2005). Optical Sensor-Based Algorithm for Crop Nitrogen Fertilization. Communications in Soil Science and Plant Analysis, 36, 2759-2781.

https://doi.org/10.1080/00103620500303988
[8] Berntsen, J., Thomsen, A., Schelde, K., Hansen, O. H., Knudsen, L., Broge, N., Hougaard, H., \& Hørfarter, R. (2006). Algorithms for sensor-based redistribution of nitrogen fertilizer in winter wheat. Precision Agriculture, 7, 65-83. https://doi.org/10.1007/s11119-006-9000-2

[9] Kitchen, N. R., Sudduth, K. A., Drummond, S. T., Scharf, P. C., Palm, H. L., Roberts, D. F., \& Vories, E. D. (2010). GroundBased Canopy Reflectance Sensing for Variable-Rate Nitrogen Corn Fertilization. Agronomy Journal, 102, 71-84. https://doi.org/10.2134/agronj2009.0114

[10] Barker, D. W. \& Sawyer, J. E. (2010). Using active canopy sensors to quantify corn nitrogen stress and nitrogen application rate. Agronomy Journal, 102(3), 964-971. https://doi.org/10.2134/agronj2010.0004

[11] Ma, B. L., Wu, T. Y., \& Shang, J. L. (2014). On-farm comparison of variable rates of nitrogen with uniform application to maize on canopy reflectance, soil nitrate and grain yield. J Plant Nutr Soil Sci., 177, 216-226. https://doi.org/10.1002/jpln.201200338

[12] López, F., Jurado, M., Álamo, S., \& García, L. (2004). Leaf nutrient spatial variability and site-specific fertilization maps within olive (Olea europaea L.) orchards. European Journal of Agronomy, 21(2), 209-222. https://doi.org/10.1016/j.eja.2003.08.005

[13] Zaman, Q. U., Schumann, A. W., \& Miller, W. M. (2005). Variable Rate Nitrogen Application in Florida Citrus Based on Ultrasonically-Sense Tree Size. Applied Engineering in Agriculture, 21(3), 331-335. https://doi.org/10.13031/2013.18448

[14] Pascual, M., Villar, J. M., Rufat, J., Rosel, J. R., Sanz, R., \& Arnó, J. (2011). Evaluation of peach tree growth characteristics under different irrigation strategies by LIDAR system: preliminary results. Acta Horticulturae, 889, 227-232. https://doi.org/10.17660/ActaHortic.2011.889.26

[15] Asner, G. P. (2004). Biophysical remote sensing signatures of arid and semiarid ecosystems: Remote sensing for natural resource management and environmental monitoring. Manual of remote sensing, 4, 53-109.

[16] Abendroth, L. J., Elmore, R. W., Boyer, M. J., \& Marlay, K. S. (2011). Corn growth and development. Iowa State University Extension, Ames, Iowa, USA, PMR 1009.

[17] Pena-Yewtukhiw, E. M., Schwab, G. J., Grove, J. H., Murdock, L. W., \& Johnson, J. T. (2008). Spatial analysis of early wheat canopy normalized difference vegetative index: determining appropriate observation scale. Agronomy Journal, 100, 454-462. https://doi.org/10.2134/agronj2007.0063

[18] Pierce, F. J. \& Nowak, P. (1999). Aspects of precision agriculture. Adv. Agronomy, 67, 1-85. https://doi.org/10.1016/S0065-2113(08)60513-1

[19] http://writingaboutcars.com/wpcontent/uploads/2015/11/Diffe rent_sensors.png

[20] http://www.ndk.com/en/sensor/ultrasonic/index.html

[21] Rovira-Más, F., Reid, J. F., Zhang, Q., \& Will, J. D. (2005). Hough transform based vision algorithm for crop row detection of an automated agricultural vehicle. Proceedings of the Institution of Mechanical Engineers, Part D. Journal of Automobile Engineering, 219(8), 999-1010. https://doi.org/10.1243/095440705X34667

[22] Giles, D. K., Delwiche, M. J., \& Dodd, R. B. (1987). Control of Orchard Spraying Based on Electronic Sensing of Target Characteristics. Trans. ASAE, 30, 1624-1630. https://doi.org/10.13031/2013.30614

[23] Giles, D. K., Delwiche, M. J., \& Dodd, R. B. (1988). Electronic Measurement of Tree Canopy Volume. Trans. ASAE, 31, 264-272. https://doi.org/10.13031/2013.30698 
[24] Giles, D. K., Delwiche, M. J., \& Dodd, R. B. (1989). Sprayer control by sensing orchard crop characteristics: orchard architecture and spray liquid savings. Journal of Agricultural Engineering Research, 43, 271-289. https://doi.org/10.1016/S0021-8634(89)80024-1

[25] Balsari, P. \& Tamagnone, M. (1998). An ultrasonic airblast sprayer. Proceedings of the International Conference on Agricultural Engineering, 585-586.

[26] Jeon, H. Y., Zhu, H., Derksen, R. C., Ozkan, H. E., Krause, C. R., \& Fox, R. D. (2011). Performance evaluation of a newly developed variable-rate sprayer for nursery liner applications. Trans. ASABE, 54(6), 1997-2007. https://doi.org/10.13031/2013.40648

[27] Doruchowski, G., Swiechowski, W., Godyn, A., \& Holownicki, R. (2011). Automatically controlled sprayer to implement spray drift reducing application strategies in orchards. J. fruit Ornam. Plant Res., 19, 175-182.

[28] Chen, Y., Ozkan, H. E., Zhu, H., Derksen, R. C., \& Krause, C. R. (2013). Spray deposition inside tree canopies from a newly developed variable-rate air-assisted sprayer. Trans. ASABE, 56, 1263-1272.

[29] Escola, A., Rosell-Polo, J. R., Planas, S., Gil, E., Pomar, J., Camp, F., Llorens, J., \& Solanelles, F. (2013). Variable rate sprayer. Part 1 orchard prototype: design, implementation and validation. Comput. Electron. Agric., 95, 122-135. https://doi.org/10.1016/j.compag.2013.02.004

[30] Sedlar, A. D., Bugarin, R. M., Nuyttens, D., Turan, J. J., \& Zoranovic, M. S. (2013). Quality and efficiency of apple orchard protection affected by sprayer type and application rate. Span. J. Agric. Res., 11, 935-944. https://doi.org/10.5424/sjar/2013114-3746

[31] Jejčič, V., Godeša, T., Hočevar, M., Širok, B., Malneršič, A., Štancar, A., Lešnik, M., \& Stajnko, D. (2011). Design and Testing of an Ultrasound System for Targeted Spraying in Orchards. Strojniški vestnik - Journal of Mechanical Engineering, 57(7-8), 587-598. https://doi.org/10.5545/sv-jme.2011.015

[32] Llorens Calveras, J., Landers, A. J., \& Larzelere, W. (2013). Precision application of pesticides in orchards - adjusting liquid flow. NY Fruit Quarterly, 21(4), 7-10.

[33] Fox, R. D., Derksen, R. C., Zhu, H., Brazee, R. D., \& Svensson, S. (2008). A history of air-blast sprayer development and future prospects. Trans. ASAB, 51(2), 405-410. https://doi.org/10.13031/2013.24375

[34] Perry, R. \& Cordero, R. (1995). Sensor controlled orchard sprayers. Proceedings of the National Conference on Pesticide Application Technology, Guelph, 164-171.

[35] Koch, H., Weisser, P., Cross, J., Gilbert, A., Glass, C., Taylor, W., Walklate, P., \& Western, N. (2000). Sensor equipped orchard spraying-efficacy, savings and drift reduction. Pesticide application, University of Surrey, Guildford, UK, 1718, 357-362.

[36] Moltó, E., Martín, B., \& Gutiérrez, A. (2000). PM-Power and Machinery: Design and testing of an automatic machine for spraying at a constant distance from the tree canopy. Journal of Agricultural Engineering Research, 77, 379-384. https://doi.org/10.1006/jaer.2000.0621

[37] Schumann, A. \& Zaman, Q. (2005). Software development for real-time ultrasonic mapping of tree canopy size. Computers and Electronics in Agriculture, 47, 25-40. https://doi.org/10.1016/j.compag.2004.10.002

[38] Solanelles, F., Escola, A., Planas, S., Rosell, J. R., Camp, F., \& Gracia, F. (2006). An electronic control system for pesticide application proportional to the canopy width of tree crops. Biosystems Eng., 95(4), 473-481. https://doi.org/10.1016/j.biosystemseng.2006.08.004

[39] Chueca, P., Garcera, C., Molto, E., \& Gutierrez, A. (2008). Development of a sensor-controlled sprayer for applying lowvolume bait treatments. Crop Protection, 27, 1373-1379. https://doi.org/10.1016/j.cropro.2008.05.004

[40] Escola, A., Planas, S. Rosell, J. R. Gràcia, F., Gil, E., \& Val, L. (2007). Variable dose rate sprayer prototype for dose adjustment in tree crops according to canopy characteristics measured with ultrasonic and laser lidar sensors. $6^{\text {th }}$ European Conference on Precision Agriculture - ECPA, Skiathos, Greece.

[41] Shirley, P. A. (1989). An introduction to ultrasonic sensing. Sensors, 6(11), 6.

[42] Escola, A., Rosell-Polo, J. R., Planas, S., Gil, E., Pomar, J., Camp, F., Llorens, J., \& Solanelles, F. (2013). Variable rate sprayer. Part 1 orchard prototype: design, implementation and validation. Comput. Electron. Agric., 95, 122-135. https://doi.org/10.1016/j.compag.2013.02.004

[43] Palleja, T. \& Landers, A. (2014). Precision Spraying in the Orchard and Vineyard: Measuring Canopy Density. New York Fruit, 22, 4.

[44] Palleja, T. \& Landers, A. (2015). Precision fruit spraying: measuring canopy density and volume for air and liquid controlT. SuproFruit - $13^{\text {th }}$ Workshop on Spray Application in Fruit Growing, Lindau, Germany, 448, 76-77.

[45] Palleja, T. \& Landers, A. J. (2016). Orchard and vineyard real time spraying adjustments using ultrasonic echoes. Aspects of Applied Biology, 132, 405-410.

[46] Palleja, T., Llorens, J., \& Landers, A. J. (2017). Measuring crop canopy - the development of a dynamic system for precision fruit crop spraying. Advances in Animal Biosciences: Precision Agriculture, 8(2), 250-254. https://doi.org/10.1017/S2040470017000905

[47] Landers, A., Palleja, T., \& Llorens, J. (2017). Technologies for the precise application of pesticides into vineyards. www.infowine-internet journal of enology and viticulture, 2/1.

[48] Li, H., Zhai C., Weckler, P., Wang, N., Yang, S., \& Zhang, B. A (2017). Canopy Density Model for Planar Orchard Target Detection Based on Ultrasonic Sensors. Sensors, 17, 31. https://doi.org/10.3390/s17010031

[49] Rosell, J. R., Llorens, J., Sanz, R., Arnó, J., Ribes-Dasi, M., Masip, J., Escolà, A., Camp, F., Solanelles, F., Gràcia, F., Gil, E., Val, L., Planas, S., \& Palacín, J. (2009). Obtaining the threedimensional structure of tree orchards from remote 2D terrestrial LIDAR scanning. Agricultural and Forest Meteorology, 149, 1505-1515. https://doi.org/10.1016/j.agrformet.2009.04.008

[50] Pfeifer, N., Gorte, B., \& Winterhalder, D. (2004). Automatic reconstruction of single trees from terrestrial laser scanner data. $20^{\text {th }}$ ISPRS Congress. Proceedings of Geo - Imagery Bridging Continents, 1682-1750.

[51] Rosell, J. R., Sanz, R., Llorens, J., Arnó, J., Escolà, A., RibesDasi, M., Masip, J., Camp, F., Gràcia, F., Solanelles, F., Pallejà, T., Val, L., Planas, S., Gil, E., \& Palacín, J. (2009). A tractor-mounted scanning LIDAR for the non-destructive measurement of vegetative volume and surface area of tree-row plantations: A comparison with conventional destructive measurements. Biosystems Engineering, 102(2), 128-134. https://doi.org/10.1016/j.biosystemseng.2008.10.009

[52] Llorens, J. \& Landers A. J. (2014). Variable rate spraying: digital canopy measurement for air and liquid electronic control. International advances in pesticide application. Aspects of Applied Biology, 114, 1- 8.

[53] Gregorio, E., Torrent, X., Planes de Marti, S., Solanelles, F., Sanz, R., Rocadenbosch, F., Masip, J., Ribes-Dasi, M., \& 
Rosell-Polo, J. (2016). Measurement of spray drift with a specifically designed lidar system. Sensors, 16(4), 499. https://doi.org/10.3390/s16040499

[54] Xiongkui, H., Aijun, Z., Yajia, L., \& Jianli, S. (2011). Precision orchard sprayer based on automatically infrared target detecting and electrostatic spraying techniques. International Journal of Agricultural and Biological Engineering, 4, 35-40.

\section{Authors' contacts:}

Davor PETROVIĆ, MSc, Assistant Faculty of Agriculture

Vladimira Preloga 1, 31000 Osijek, Croatia

pdavor@pfos.hr

Mladen JURIŠIĆ, PhD, Full Professor

Faculty of Agriculture

Vladimira Preloga 1, 31000 Osijek, Croatia

mjurisic@pfos.hr

Vjekoslav TADIĆ, PhD, Assistant Professor (corresponding author)

Faculty of Agriculture

Vladimira Preloga 1, 31000 Osijek, Croatia

vtadic@pfos.hr

Ivan PLAŠČAK, PhD, Assistant Professor Faculty of Agriculture

Vladimira Preloga 1, 31000 Osijek, Croatia

iplascak@pfos.hr

Željko BARAČ, MSc, Assistant

Faculty of Agriculture

Vladimira Preloga 1, 31000 Osijek, Croatia

zbarac@pfos.hr 